\title{
Nitrogen fixation by Plectonema boryanum has a photosystem II independent component
}

\author{
H. S. Misra and Rakesh Tuli† \\ Author for correspondence: Rakesh Tuli. Fax: +91522 244330.
}

Molecular Biology and Agriculture Division, Bhabha Atomic Research Centre, Bombay 400 085, India

\begin{abstract}
The non-heterocystous filamentous cyanobacterium Plectonema boryanum showed a several-fold decline in photosystem II dependent $\mathrm{O}_{2}$ evolution during the diazotrophic phase of growth. A sharp fall in the amounts of lightharvesting pigments and an uncoupling between the electron transfer from the photosystem II complex to the quinone acceptors may lead to the depression of light-dependent $\mathrm{O}_{2}$ evolution during the diazotrophic phase. Nitrogen fixation as well as $\mathrm{CO}_{2}$ fixation required light, but were partly supported independently of photosystem II. A stimulation of photosystem I and a depression of photosystem II occurred during the diazotrophic phase of a nitrogen-fixing culture of $P$. boryanum.
\end{abstract}

Keywords: nitrogen fixation, photosystem II, cyanobacterium, Plectonema boryanum

\section{INTRODUCTION}

Certain cyanobacteria are unique in their ability to conduct two mutually incompatible functions: $\mathrm{O}_{2}$-evolving photosynthesis and $\mathrm{O}_{2}$-labile nitrogen fixation. Some diazotrophic cyanobacteria compartmentalize nitrogen fixation in morphologically differentiated cells called heterocysts which lack photosystem II and ribulose biphosphate carboxylase and have greatly reduced phycocyanin (reviewed by Haselkorn, 1978). Among nonheterocystous cyanobacteria, temporal separation of nitrogen fixation from photosynthesis has been proposed as a major mechanism in Gloeothece (Gallon et al., 1974; Mitsui et al., 1986), Oscillatoria (Stal \& Krumbein, 1985) and Synechococcus (Mitsui et al., 1987) to protect nitrogenase from $\mathrm{O}_{2}$ evolved during photosynthesis. The molecular basis of the temporal separation of photosynthesis and nitrogen fixation is not known.

Plectonema boryanum is a filamentous, non-heterocystous cyanobacterium that fixes nitrogen only under microaerobic conditions (Stewart \& Lex, 1970). When grown microaerobically under nitrogen-starvation conditions in continuous light it shows alternating cycles of photosynthesis and nitrogen fixation (Rai et al., 1992; Misra \& Tuli, 1993). Studies on the relationship between photosynthesis and nitrogen fixation have remained rather

† Present address: Centre for Plant Molecular Biology, National Botanical Research Institute, Rana Pratap Marg, Lucknow 226 001, India.

Abbreviations: DCMU, 3(3,4-dichlorophenyl)-1,1-dimethylurea; DCPIP, 2,6-dichlorophenyl indophenol; DCQ, 2,6-dichloro-p-benzoquinone. neglected for such microaerobically diazotrophic cyanobacteria, apparently due to difficulties in developing culture conditions that allow their sustained growth under nitrogen-starvation conditions (Giani \& Krumbein, 1986). This report describes studies with rapidly growing nitrogen-fixing cultures of $P$. boryanum. Under such conditions, the period of maximum nitrogen fixation was accompanied by a substantial inhibition of photosystem II activity due to a shift in coupling between the two photosystems. During this period, both $\mathrm{CO}_{2}$ fixation and nitrogen fixation were partly independent of photosystem II.

\section{METHODS}

Organism and growth conditions. P. boryanum UTEX 594 is from the University of Texas Collection. Under nitrogensufficient conditions, it was grown in BG11 medium (Rippka et al., 1979) at $25 \pm 2{ }^{\circ} \mathrm{C}$ bubbled with filtered air under continuous illumination as described by Vachhani et al. (1993). To establish a nitrogen-fixing culture, the BG11-grown culture was washed twice with $\mathrm{BG} 11_{0}$ medium (containing no combined nitrogen) and inoculated aseptically into 151 of $B G 11_{0}$ in a fermenter vessel (Microferm Fermentor, New Brunswick Scientific) at $\mathrm{OD}_{750} 0 \cdot 1$. The culture was stirred continuously at 150 r.p.m. and bubbled with $\mathrm{N}_{2}$ (Iolar 2, Indian Oxygen) at $700 \mathrm{ml} \mathrm{min}^{-1}$ and $\mathrm{CO}_{2}$ at $5 \mathrm{ml} \mathrm{min}^{-1}$ through independent inlets. The culture was illuminated with white fluorescent tube lights all placed on one side, covering one-half of the fermenter vessel circumference. The temperature of the culture was maintained by circulating water at $25 \pm 2{ }^{\circ} \mathrm{C}$ through the cooling jacket. The incident light at the surface of the tube lights was $8400 \mathrm{~lx}$ (model ANA 999 lux meter, Tokyo Photoelectric Co.). Establishment of cultures of $P$. boryanum with sustained, photautotrophic, diazotrophic growth has been reported (Misra \& Tuli, 1993). 
Measurement of dissolved $\mathrm{O}_{2}$. On-line dissolved $\mathrm{O}_{2}$ (steadystate $\mathrm{dO}_{2}$ ) was continuously monitored with a Clark-type oxygen electrode installed in the fermenter vessel. Lightdependent $\mathrm{O}_{2}$ evolution by the cyanobacterium was measured using an oxygraph (Gilson Medical Electronics) on an aliquot drawn from the fermenter and resuspended to $\mathrm{OD}_{750} 3.0$ in BG11 containing $50 \mathrm{mM}$ HEPES/ $\mathrm{NaOH}$ pH 7.5. The surface of the water-jacketed cell of the oxygraph received $5400 \mathrm{~lx}$ of water-cooled tungsten light which provided saturating light intensity for $\mathrm{O}_{2}$ evolution. The culture was concentrated in air and was equilibrated in the dark for $5 \mathrm{~min}$ before measuring light-dependent $\mathrm{O}_{2}$ evolution. Photosystem II activity was measured as light-dependent $\mathrm{O}_{2}$ evolution in the presence of $3 \mathrm{mM} \mathrm{MgCl}_{2}$ and $1.5 \mu \mathrm{M}$ gramicidin with or without $500 \mu \mathrm{M}$ DCQ (2,6-dichloro- $p$-benzoquinone). $\mathrm{O}_{2}$ evolution was completely inhibited immediately under all culture conditions following the addition of DCMU [3(3,4-dichlorophenyl)-1,1dimethylurea] at $10 \mu \mathrm{M}$. Photosystem I activity was measured as light-dependent $\mathrm{O}_{2}$ uptake, driven by $50 \mu \mathrm{M}$ methyl viologen in a reaction mixture containing $50 \mathrm{mM}$ HEPES/ $\mathrm{NaOH}$ pH $7 \cdot 5$, $50 \mu \mathrm{M}$ DCPIP (2,6-dichlorophenol indophenol), $500 \mu \mathrm{M}$ sodium ascorbate, $10 \mu \mathrm{M} \mathrm{NaCN}, 50 \mu \mathrm{M} \mathrm{NaN}$ and $10 \mu \mathrm{M}$ DCMU.

Photosynthetic $\mathrm{CO}_{2}$ fixation. This was determined on an aliquot of the cyanobacterial culture resuspended as above. Acid-stable ${ }^{14} \mathrm{CO}_{2}$ incorporation was determined in the presence of $5 \mu \mathrm{Ci} \mathrm{NaH}{ }^{14} \mathrm{CO}_{3} \mathrm{ml}^{-1}\left(951 \mathrm{mCi} \mathrm{mmol}^{-1} ; 35 \cdot 2 \mathrm{GBq} \mathrm{mmol}^{-1}\right)$, and $5 \mathrm{mM}$ unlabelled $\mathrm{NaHCO}_{3}$ at $30^{\circ} \mathrm{C}$ following exposure to $5500 \mathrm{~lx}$ (saturating light intensity for $\mathrm{CO}_{2}$ fixation) tungsten light. The culture was equilibrated in the dark for $5 \mathrm{~min}$ before measuring $\mathrm{CO}_{2}$ fixation. Aliquots were drawn after a $5 \mathrm{~min}$ exposure to light. ${ }^{14} \mathrm{C}$ incorporation was linear up to at least $12 \mathrm{~min}$ of exposure. Photosystem II independent $\mathrm{CO}_{2}$ fixation was monitored in the presence of $10 \mu \mathrm{M}$ DCMU.

Pigments. Phycocyanin content was estimated in the supernatant of sonicated cell suspensions after precipitating the membranes with $1 \%(\mathrm{w} / \mathrm{v})$ streptomycin sulfate (Tandeau de Marsac \& Houmard, 1988). Chlorophyll was extracted in methanol and estimated as described by MacKinney (1941).

Measurement of thermoluminescence. Aliquots of $0.6 \mathrm{ml}$ samples suspended to $\mathrm{OD}_{750} 3.0$ (as described above) were immobilized on $2.5 \mathrm{~cm}$ diameter Whatman GF/C filter paper discs and placed in stainless steel planchets. The samples were dark-adapted for $3 \mathrm{~min}$ before freezing to $77 \mathrm{~K}$. Glow curves were recorded for samples frozen as such or frozen after the addition of methyl viologen $(50 \mu \mathrm{M})$ (Rutherford et al., 1984).

Fluorescence measurements. For $77 \mathrm{~K}$ fluorescence measurements, the cyanobacterial culture was sampled in the photosynthetic and diazotrophic phases. The culture was resuspended to a chlorophyll concentration of $5 \mu \mathrm{g} \mathrm{ml}^{-1}$ in BG11 containing $50 \mathrm{mM}$ HEPES/ $\mathrm{NaOH}$ pH 7.5, transferred to capillary tubes, dark-adapted for $30 \mathrm{~min}$, frozen in liquid $\mathrm{N}_{2}$ and used for recording fluorescence spectra using a Perkin Elmer LS-5 instrument (Allen et al., 1985).

Nitrogenase activity. An acetylene reduction assay was carried out by a method similar to that of David \& Fay (1977) except that it was conducted anaerobically. A $2 \mathrm{ml}$ sample of $P$. boryanum culture was drawn anaerobically from the fermenter and injected into a $5 \mathrm{ml}$ vial containing an $\mathrm{N}_{2}$ atmosphere. The assay was initiated by replacing $0.5 \mathrm{ml}$ of the gas phase with acetylene. The vials were rotated in the presence of $2000 \mathrm{~lx}$ light from tungsten lamps for $30 \mathrm{~min}$ before the assay was terminated by injecting $0.5 \mathrm{ml} 10 \%(\mathrm{w} / \mathrm{v})$ TCA. Ethylene was resolved on Porapak $\mathrm{T}$ and detected by flame ionization.

\section{RESULTS AND DISCUSSION}

In the presence of continuous light $(8400 \mathrm{~lx}) P$. boryanum grew microaerobically under nitrogen-starvation conditions (Fig. 1a) by conducting nitrogen fixation and photosynthesis in alternate cycles (Fig. 1b). The doubling time under such conditions of growth was $57 \pm 4 \mathrm{~h}$. Dissolved $\mathrm{O}_{2}$ in the culture medium declined from 35-60 $\mu \mathrm{M}$ during the peak of a preceding photosynthetic phase to $13-17 \mu \mathrm{M}$ before nitrogenase activity began to appear. The decline in $\mathrm{dO}_{2}$ was accompanied by a parallel sharp decline in phycocyanin (Fig. 1a) and a several-fold decline in light-dependent $\mathrm{O}_{2}$ evolution (Table 1). Lightdependent $\mathrm{O}_{2}$ evolution by samples taken during the diazotrophic phase was stimulated 1.5- to 2-fold following the addition of DCQ (Table 1) in the oxygraph cell. The DCQ-mediated stimulation was not seen when the culture was in the photosynthetic phase. The results suggested a possible alteration in the photosystem II complex during the diazotrophic phase, resulting in inefficient electron flow to quinone acceptors. Alternatively, oxidation of the reduced plastoquinone pool may be blocked during the nitrogen-fixation phase, leading to inhibition of electron flow to plastoquinones. To distinguish between these alternatives, thermoluminescence glow curves and fluorescence emission were examined for cultures growing in the photosynthetic and diazotrophic phases.

Thermoluminescence data on the periodicity of oscillations following flash excitation (H. S. Misra \& T. S. Desai, unpublished) showed no functional differences in the donor side ( $\mathrm{S}$ states) of the water-oxidizing complex in cultures growing in the diazotrophic and photosynthetic

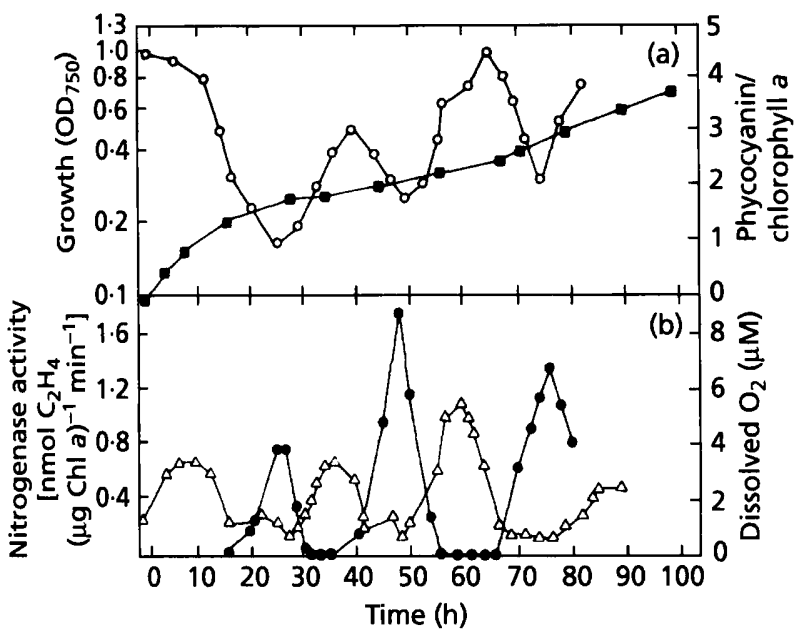

Fig. 1. Metabolic pattern in P. boryanum UTEX 594 growing in continuous light under nitrogen-fixing conditions. Growth ( $\square$ ), ratio of phycocyanin to chlorophyll a (O), steady-state dissolved oxygen $(\triangle)$ and acetylene reduction activity $(0)$ are shown for a typical experiment during the first $4 \mathrm{~d}$ growth following inoculation. Chlorophyll a increased gradually with growth of the culture; the values were $0.58,0.58,0.59,0.59,0.72$ and $0.79 \mu \mathrm{g} \mathrm{ml}^{-1}$ at $0,26,40,50,62$ and $72 \mathrm{~h}$ respectively. The corresponding values for phycocyanin at these time points were

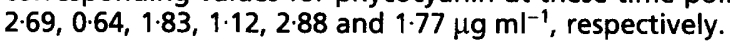


Table 1. Stimulation of $\mathrm{O}_{2}$ evolution by DCQ during the diazotrophic phase

All values \pm standard deviation are means of five to seven aliquots drawn from cultures in three independent experiments. The steady-state $\mathrm{dO}_{2}$ in the fermenter at the time of drawing the aliquots was $15-18 \mu \mathrm{M}$ during the diazotrophic phase and $40-80 \mu \mathrm{M}$ during the photosynthetic phase of cultures growing under nitrogen-fixing conditions. Comparative values for oxygen evolution in a nitrate-grown culture were $3340 \pm 442 \mathrm{nmol} \mathrm{O}_{2}(\mathrm{mg} \mathrm{Chl} a)^{-1} \mathrm{~min}^{-1}$.

\begin{tabular}{|c|c|c|c|c|}
\hline \multirow[t]{2}{*}{$\begin{array}{l}\text { Growth } \\
\text { phase }\end{array}$} & \multicolumn{2}{|c|}{$\begin{array}{c}\mathrm{O}_{2} \text { evolution }\left[\mathrm{nmol} \mathrm{O}_{2}\right. \\
\left.(\mathrm{mg} \mathrm{Chl} a)^{-1} \mathrm{~min}^{-1}\right]\end{array}$} & \multirow{2}{*}{$\begin{array}{l}\text { Nitrogenase } \\
\text { activity } \\
{\left[\mathrm{nmol} \mathrm{C} \mathrm{H}_{4}\right.} \\
(\mu \mathrm{g} \mathrm{Chl} a)^{-1} \\
\left.\min ^{-1}\right]\end{array}$} & \multirow{2}{*}{$\begin{array}{c}\mathrm{CO}_{2} \text { fixation } \\
{[\mathrm{nmol} \mathrm{CO}} \\
(\mathrm{mg} \mathrm{Chl} a)^{-1} \\
\left.\min ^{-1}\right]\end{array}$} \\
\hline & $-\mathbf{D C Q}$ & $+\mathbf{D C Q}$ & & \\
\hline $\begin{array}{l}\text { Diazotrophic } \\
\text { Photosynthetic }\end{array}$ & $\begin{array}{c}286 \pm 40 \\
2665+802\end{array}$ & $\begin{array}{c}592 \pm 85 \\
2620+520\end{array}$ & $\begin{array}{l}3 \cdot 5 \pm 1 \cdot 3 \\
0\end{array}$ & $\begin{array}{l}1242 \pm 334 \\
2685+591\end{array}$ \\
\hline
\end{tabular}

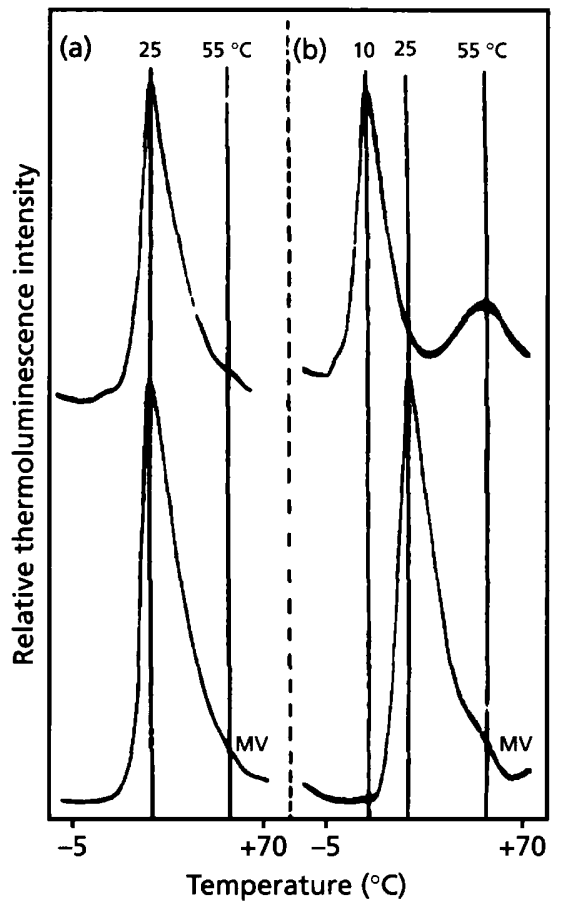

Fig. 2. Thermoluminescence glow curves for $P$. boryanum UTEX 594 sampled during the photosynthetic phase (a) and the diazotrophic phase (b) of growth under nitrogen-fixing conditions. The glow curve for the diazotrophic phase was recorded at double the sensitivity of that for the photosynthetic phase. The lower traces are glow curves for the corresponding samples to which methyl viologen (MV) was added.

phases. The thermoluminescence glow curves showed striking differences, implying differences in the nature of plastoquinone pools in the two phases. The major DCMU-sensitive band appeared at $25^{\circ} \mathrm{C}$ in the photosynthetic phase but at $10^{\circ} \mathrm{C}$ in the diazotrophic phase (Fig. 2). A shift to a lower temperature can result from a fall in redox potential between $\mathrm{Q}_{\mathrm{B}} / \mathrm{Q}_{\mathrm{B}}{ }^{-}$and $\mathrm{Q}_{\mathrm{A}} / \mathrm{Q}_{\mathrm{A}}{ }^{-}$(Demeter et al., 1985). Methyl viologen shifted the band back to $25^{\circ} \mathrm{C}$ in the diazotrophic phase, but made no change to the $25^{\circ} \mathrm{C}$ band in the photosynthetic phase. These results imply an impairment in electron flow between $Q_{A}$ and $Q_{B}$ (i.e. the acceptor side of photosystem II) during the diazotrophic phase (H. S. Misra \& T. S. Desai, unpublished). Halogenated benzoquinones like DCQ are known to overcome such impairment (Graan \& Ort, 1986). Thus the intracellular nitrogen status (or the ratio of carbon to nitrogen) appeared to regulate the redox levels of secondary quinone acceptor $\mathrm{Q}_{\mathrm{B}}$, leading to the impairment of electron transfer from the $\mathrm{O}_{2}$-evolution complex. The function was restored once sufficient intracellular nitrogen had accumulated by the end of the diazotrophic phase. This marked the beginning of the photosynthetic phase, leading to 8- to 9-fold higher light-dependent $\mathrm{O}_{2}$ evolution and 2- to 2.5-fold higher $\mathrm{CO}_{2}$ fixation (Table 1 ).

The $77 \mathrm{~K}$ fluorescence emission spectra showed distinct changes in emission by phycocyanin $\left(F_{645}\right)$ and photosystem I $\left(\mathrm{F}_{\mathbf{7 2 6}}\right)$, as the growth phase changed from photosynthetic to diazotrophic. In the photosynthetic phase, $F_{645}$ was higher and $F_{726}$ was lower than the corresponding values in the diazotrophic phase. Thus, in the diazotrophic phase there were spectral changes (Fig. 3 ) indicative of lower phycocyanin and altered excitation energy distribution, apparently in favour of photosystem I. In Synechococcus sp. PCC 6301, redox-controlled phosphorylation of certain polypeptides has been suggested to induce electrostatic decoupling of the phycobilisomes from photosystem II and their closer association with photosystem I (Allen et al., 1985).

Though depression in photosystem II preceded the phase of nitrogenase activity, light was an absolute requirement for sustained nitrogen fixation. In the presence of DCMU at levels that completely inhibited light-dependent $\mathrm{O}_{2}$ evolution within seconds (data not given), nitrogenase activity was not affected during the $5 \mathrm{~h}$ period of observation, provided the culture was incubated in the presence of light (Fig. 4). Incubation of the culture in the dark resulted in a gradual decline of nitrogenase activity, reaching $20 \%$ of the initial level after $4 \mathrm{~h}$ (or longer, in certain experiments) of incubation plus a 30 min assay in 


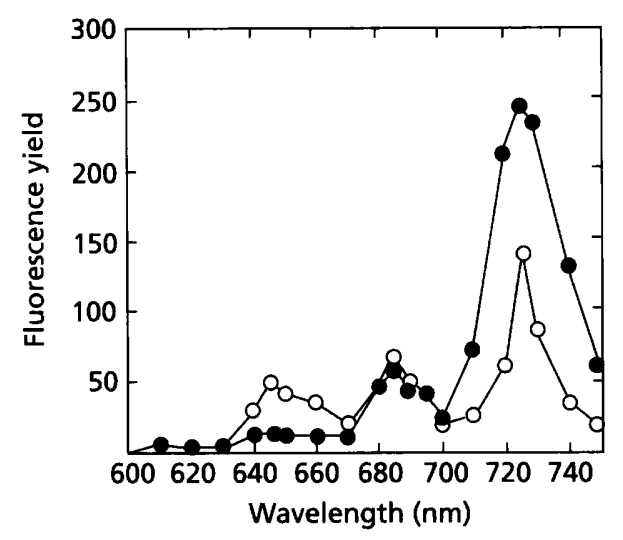

Fig. 3. Normalized $77 \mathrm{~K}$ fluorescence emission spectra of $P$. boryanum UTEX 594 culture at excitation wavelength $435 \mathrm{~nm}$. The fluorescence yield (arbitrary units) is plotted for the culture sampled in the photosynthetic phase (O) and the diazotrophic phase (O) of growth.

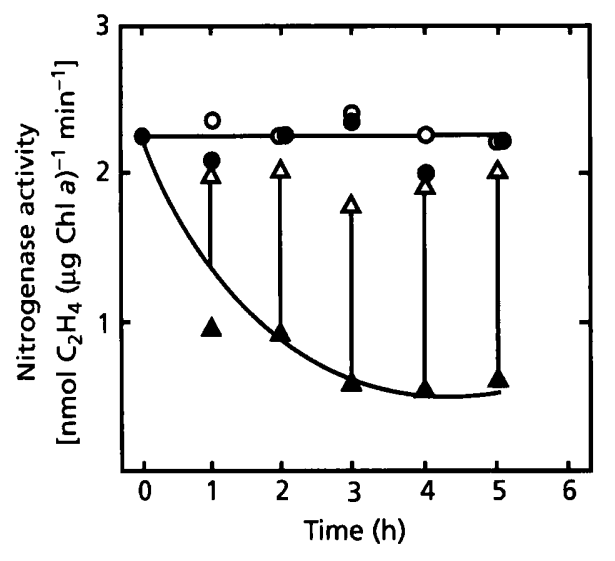

Fig. 4. Photosystem II independent light requirement for nitrogen fixation in $P$. boryanum UTEX 594 . Three $500 \mathrm{ml}$ aliquots of an actively nitrogen-fixing culture in the diazotrophic phase were drawn from the fermenter vessel. These were bubbled with a mixture of $\mathrm{N}_{2}$ and $\mathrm{CO}_{2}$ (as described in Methods) and incubated as follows: in the light in the absence

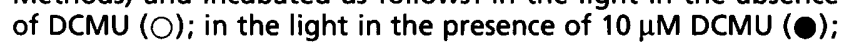
in the dark in the presence of $10 \mu \mathrm{M}$ DCMU ( $\boldsymbol{A})$. Subsamples were removed anaerobically at the times indicated and nitrogenase assays performed (in triplicate) using the same conditions of light and DCMU as the sampled culture. A second set of subsamples from the culture incubated in the dark with $10 \mu \mathrm{M}$ DCMU was assayed (in triplicate) in the light with $10 \mu \mathrm{M}$ $\operatorname{DCMU}(\triangle)$.

the dark. However, at all time points through this period, the culture showed restoration of nitrogenase activity (despite the presence of DCMU) when the $30 \mathrm{~min}$ assay was conducted in the light (Fig. 4). The results imply light dependence of nitrogenase activity in a manner that is independent of photosystem II. The sources of reducing power and ATP may accumulate during the photosynthetic phase to support nitrogenase activity during the diazotrophic phase when photosystem II is depressed.
Table 2. Light-dependent, photosystem II independent $\mathrm{CO}_{2}$ fixation by $P$. boryanum during the diazotrophic phase

An aliquot of culture during a given phase of growth was drawn from the fermenter vessel and incubated in the dark in the presence of $10 \mu \mathrm{M}$ DCMU for $30 \mathrm{~min}$ before being assayed for $\mathrm{CO}_{2}$ fixation. The results were comparable even if the period of preincubation in DCMU was extended to $2 \mathrm{~h}$. Other details were similar to those in the legend to Table 1.

\begin{tabular}{|c|c|c|}
\hline \multirow[t]{2}{*}{$\begin{array}{l}\text { Growth } \\
\text { conditions }\end{array}$} & \multicolumn{2}{|c|}{$\begin{array}{c}\mathrm{CO}_{2} \text { fixation } \\
{[\mathrm{nmol} \mathrm{CO}} \\
\left.(\mathrm{mg} \mathrm{Chl} a)^{-1} \mathrm{~min}^{-1}\right]\end{array}$} \\
\hline & Light & $\begin{array}{l}\text { Light + } \\
\text { DCMU }\end{array}$ \\
\hline $\begin{array}{l}\text { Nitrate-grown culture } \\
\mathrm{N}_{2} \text {-fixing culture }\end{array}$ & $2705 \pm 322$ & $43 \pm 5$ \\
\hline Diazotrophic phase & $1342 \pm 202$ & $660 \pm 97$ \\
\hline Photosynthetic phase & $2742 \pm 466$ & $334 \pm 74$ \\
\hline
\end{tabular}

Smoker \& Barnum (1990) reported an eight- to tenfold increase in glycogen reserves in cultures of $P$. boryanum incubated aerobically under nitrogen starvation conditions compared with cultures grown in the presence of combined nitrogen. Nitrogen-starved cultures utilized glycogen reserves when a microaerophilic environment was provided to allow the onset of nitrogen fixation. Studies are in progress on the level of glycogen in different phases of growth of $P$. boryanum UTEX 594 under the growth conditions used by us and the enhancement of nitrogenase activity by exogenous carbon sources.

While nitrogen-fixing cultures showed a substantial level of photosystem II independent nitrogenase activity, some light-dependent $\mathrm{CO}_{2}$ fixation was also supported despite inhibition of photosystem II by DCML (Table 2). In a microaerobically grown nitrogen-fixing culture, DCMU inhibited $\mathrm{CO}_{2}$ fixation by approximately $50 \%$ during the diazotrophic phase and by about $90 \%$ during the photosynthetic phase, during the $2 \mathrm{~h}$ period of observation, following the addition of DCMU. On the other hand, DCMU inhibition of $\mathrm{CO}_{2}$ fixation, in a culture grown aerobically with excess combined nitrogen (nitrate-grown culture), was nearly complete (Table 2). The results suggest a partial shift in the source of reductant from photosystem II to an endogenous donor in cultures grown under nitrogen-starvation conditions. The shift is most marked during the diazotrophic phase of growth of a culture grown under nitrogen-fixing conditions.

Light dependence, but photosystem II independence, of nitrogen fixation and the $77 \mathrm{~K}$ fluorescence emission changes in the $\mathrm{F}_{\mathbf{7 2 6}}$ component imply the involvement of photosystem $I$ in $P$. boryanum during the diazotrophic phase, for both nitrogenase activity and $\mathrm{CO}_{2}$ fixation. In a nitrogen-fixing culture, photosystem I activity (estimated as methyl-viologen-dependent $\mathrm{O}_{2}$ evolution in the 
PS Il independent component of nitrogen fixation

light in the presence of DCMLi and reduced DCPIP) was about 30-40\% higher during the diazotrophic phase than that in the photosynthetic phase: $163 \pm 54$ versus $114 \pm 34 \mathrm{nmol} \mathrm{O}_{2}(\mathrm{mg} \mathrm{Chl} a)^{-1} \mathrm{~min}^{-1}$; means significantly different at $2 \cdot 04 \%$ (Student's $t$-test). The photosystem I activity of a culture grown aerobically with nitrate as a source of abundantly available combined nitrogen was $111 \pm 22 \mathrm{nmol} \mathrm{O}_{2}(\mathrm{mg} \mathrm{Chl} \mathrm{a})^{-1} \mathrm{~min}^{-1}$, comparable to that of the nitrogen-fixing culture in the photosynthetic phase.

Our results imply that the decline in photosyntheric $\mathrm{O}_{2}$ evolution during nitrogen-fixing growth of $P$. boryanum was due to degradation of light-harvesting pigments and a block in electron flow from photosystem II. This allowed the cyanobacterium to reduce intracellular $\mathrm{O}_{2}$ evolution to levels non-deleterious to nitrogenase. A substantial level of nitrogenase activity was photosystem II inclependent (DCML resistant) but light requiring. Possibly, the endogenous reductants accumulated during the photosynthetic phase provided electrons to photosystem I. The accumulated substrates were utilized for nitrogenase function and partly for $\mathrm{CO}_{2}$ fixation.

Continued tixation of $\mathrm{CO}_{2}$ in spite of a substantial decline in light-dependent $\mathrm{O}_{2}$ evolution during the diazotrophic phase resulted in a major deviation of the stoichiometry from 1:1. It will be interesting to study the pathway of signal transduction that shifts coupling of photosystem I from photosystem Il to endogenous electron donors even during photoautotrophic growth. Light-dependent donation of electrons by $\mathrm{NADPH}, \mathrm{NADH}$ or organic acids to methy] viologen via photosystem 1 has been reported for cell-free membrane preparations from cyanobacteria including P. boryanum (Murai \& Katoh, 1975; Matthijs $e t$ al., 1984), Cblamydomonas (Godde, 1982) and greening potato tubers (Janave et al., 1991). light-dependent utilization of reduced carbon sources by certain cyanobacteria, including Agmenellum (Lambert \& Stevens, 1986), Synechocystis (Jansson et al., 1987), Pleitonema (Smoker \& Barnum, 1990) and Oscillatoria (Gallon et al., 1991), has been reported. However, in these studies, photosystem II independent photoheterotrophic growth was demonstrated under conditions that inhibited photosynthesis, i.e. the inclusion of DCMU or the depletion of $\mathrm{CO}_{2}$. ()ur study suggests that photosystem II independent pathways of light-dependent electron transfer may have a functional significance under certain stress conditions that lead to depression of photosy'stem 11 - as under nitrogenstarvation conditions in a microaerobically nitrogenfixing cyanobacterium, like $P$. boryanum.

Once sufficient nitrogen had been fixed, the cyanobacterium enhanced its ability to harvest light by raising the level of phycocyanins, reactivated its electron transfer, and therefore entered the photosynthetic phase. Thus oscillations in intracellular nitrogen (or the ratio of carbon to nitrogen) lead to alternating phases of photosynthesis and nitrogen fixation. The molecular and genetic basis that triggers such a metabolic rhythm leading to cyclic temporal separation of the two mutually incompatible physiological processes is not known. P. boryanum provides an attractive system for such studies since a mobilizable plasmid vector has recently become available (Vachhani et al., 1993) for this cyanobacterium.

\section{ACKNOWLEDGEMENT}

The authors are grateful to Professor Prasanna Mohanthy, JNL', New Delhi, for his help with the fluorescence cmission studics.

\section{REFERENCES}

Allen, J. F., Christine, E. S. \& Holmes, N. G. (1985). Correlation of membrane protein phosphorylation with excitation energy distribution in the cyanobacterium Synebsococtus 63011. HI:BS I.e/l 193, 271275 .

David, K. A. V. \& Fay, P. (1977). liffects of long-term treatment with acetylene on nitrogen-fixing microorganisms. App/ Liniron Mitrobiol 34, 640646.

Demeter, S., Vass, E. H. \& Sallai, A. (1985). Comparative thermoluminescence study of triazine-resistant and -susceptible biotypes of I:rigeran canadensis I. Biochim Bioply.s Acti 806, 16- 24.

Gallon, J. R., Larue, T. A. \& Kurz, W. G. W. (1974). Photosynthesis and nitrogenase activity in the bluc-green alga Ciloocapia. (an I Aicrobiol 20, 1633-1637.

Gallon, J. R., Hashem, M. A. \& Chaplin, A. E. (1991). Nitrogen fixation by Oscillatoria spp. under auterophic and photohetero. trophic conditions. I Gen licrobiol 137, 31.39.

Giani, D. \& Krumbein, W. E. (1986). Grow th characteristics of nonheterocystous cyannbacterium Plectomema borranom with $\perp_{2}$ as nitrugen source. Arch Microbio/ 145, 259265

Godde, D. (1982). light dependent $\mathrm{NADH}$ oxidarion by a chloroplast fraction of Chlamydomonas reinbardii (X)-15. .4rch Microbiol 131, 197202.

Graan, T. \& Ort, D.R. (1986). Derection of oxygen-cuolving photosystem II centers inactive in plastoquinone reduction. Biochim Bioptys Acta 852, 320330 .

Haselkorn, R. (1978). Hetcrocysts. Inmu Rer Plant Physiol 29 , 319344

Janave, M. T., Ramaswamy, N. K. \& Nair, P. M. (1981). (harac terization of endogenous electron donor systems to photosystem $I$ in green porato tuber chioroplasts. Plant Sii 76, 79 84.

Jansson, C., Debus, R. J., Osiewacz, H. D., Gurevitz, M. \& Mcintosh, L. (1987). (onstruction of an obligate photoheterotrophic mutant of the cyanobacterium fymeibocystis 68013. Plant Pbyiriol 85, 10211025.

Lambert, D. H. \& Stevens, S., Jr (1986). Photoheterotrophic growth of . 4 gmentlum quadruplicatum PR -6. I Batteriol 165, 6.546 .56$.

Mackinney, G. (1941). Absorption of light by chiorophyll solutions. J Biol Cbem 140, 315322.

Matthijs, H. C. P., Luderus, E. M. E., Scholts, M. J. C. \& Kraayenhof, R. (1984). linergy metabolism in the cyanobacterium Plectonema borrantum: oxidative phosphorylatien and respiratory pathways. Biochim Biophss Aita 766, 3844.

Misra, H. S. \& Tuli, R. (1993). Photosystem II independent carbon dioxide fixation in Plectonema borzanim during photouatotrophic growth under nitrogen fixing conditions. I Plamt Biochem Biotechnol 2, 101104.

Mitsui, A., Kumazawa, S., Takahashi, A., Ikemoto, H., Cao, S. \& Arai, T. (1986). Strategy by which nitrogen-fixing unicellular cyanobacteria grow photoautotrophically, Nature 323, :20 -22.

Mitsui, A., Cao, S., Takahashi, A. \& Arai, T. (1987). (iruwth sinchrony and cellular parameters of the unicellular nierogen-tixing 
marine cyanobacterium, Synechococcus sp. strain Miami BG 043511 under continuous illumination. Physiol Plant 69, 1-8.

Murai, T. \& Katoh, T. (1975). Photosystem I-dependent oxidation of organic acids in blue-green alga, Anabaena variabilis. Plant Cell Physiol 16, 789-797.

Rai, A. N., Borthakur, M. \& Bergman, B. (1992). Nitrogenase derepression, its regulation and metabolic changes associated with diazotrophy in the non-heterocystous cyanobacterium Plectonema boryanum PCC 73110. J Gen Microbiol 138, 481- 491.

Rippka, R., Deruelles, J., Waterbury, J. B., Herdman, M. \& Stanier, R. Y. (1979). Genetic assignments, strain histories and properties of pure cultures of cyanobacteria. J Gen Microbiol 111, 1-61.

Rutherford, A. W., Renger, G., Koike, H. \& Inoue, Y. (1984). Thermoluminescence as a probe of PS II. The redox and protonation states of secondary acceptor quinone and the oxygen evolving enzyme. Biochim Biophys Acta 767, 548-556.

Smoker, J. A. \& Barnum, S. R. (1990). Nitrogen fixation activity of a filamentous non-heterocystous cyanobacterium in the presence and absence of exogenous, organic substrates. Arch Microbiol 153, 417-421.

Stal, L. J. \& Krumbein, W. E. (1985). Nitrogenase activity in the non-heterocystous cyanobacterium Oscillatoria $s p$. grown under alternating light-dark cycles. Arch Microbiol 143, 67-71.

Stewart, W. D. P. \& Lex, M. (1970). Nitrogenase activity in the blue-green alga Plectonema boryanum strain 594. Arch Microbiol 73, 250-260.

Tandeau de Marsac, N. \& Houmard, J. (1988). Complementary chromatic adaptation: physiological condition and action spectra. Methods Enqymol 167, 318-328.

Vachhani, A. K., lyer, R. K. \& Tuli, R. (1993). A mobilizable shuttle vector for the cyanobacterium Plectonema boryanum. J Gen Microbiol 139, 569-573.

Received 21 June 1993; revised 11 October 1993; accepted 11 November 1993. 